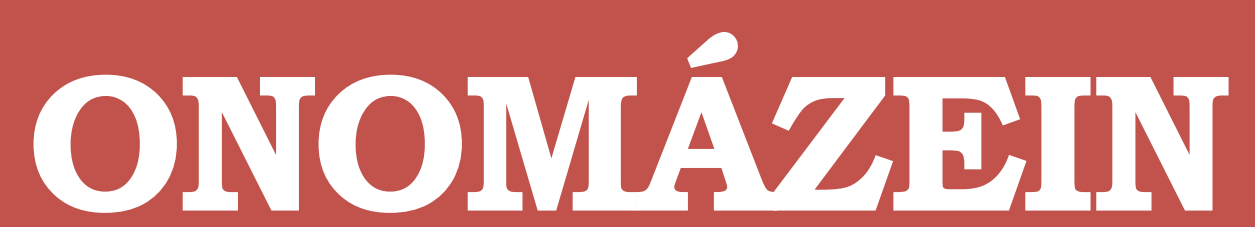

Revista de lingüística, filología y traducción
PONTIFICIA UNIVERSIDAD CATÓLICA DE CHILE FACULTAD DE LETRAS

\title{
Alcances y límites de un mapa prosódico
}

Scope and limits of a prosodic map

\section{Domingo Román}

Universidad de Santiago de Chile Chile

\section{Diana Muñoz-Builes}

Pontificia U. Católica de Chile Chile

\section{Camilo Quezada}

Universidad de Chile

Chile

\section{José Joaquín Atria}

Chile

ONOMÁZEIN 49 (septiembre de 2020): 21-39

DOI: 10.7764/onomazein.49.02

ISSN: 0718-5758

\section{(c) $($ i $\ominus$}

Domingo Román: Departamento de Lingüística y Literatura, Universidad de Santiago de Chile, Chile. | E-mail: domingo.roman@usach.cl

Diana Muñoz-Builes: Departamento de Ciencias del Lenguaje, Pontificia Universidad Católica de Chile, Chile. | E-mail: dmmunoz2@uc.cl

Camilo Quezada: Universidad de Chile, Chile. I E-mail: cequezadgap@gmail.com José Joaquín Atria: Chile. | E-mail: jjatria@gmail.com 


\section{Resumen}

El presente artículo tiene como objetivo presentar el primer "Mapa prosódico de Chile", un proyecto de largo alcance que pretende documentar y describir, fonética y fonológicamente, los rasgos suprasegmentales del español hablado por chilenos. Para entender su dimensión, se proporciona una caracterización de los mapas prosódicos que se encuentran actualmente en curso, tales como AMPER, ATLES y otros relacionados, analizando los parámetros estudiados en cada uno de ellos y enfatizando en sus fundamentos, orientaciones y alcances. Finalmente, se incluye una reflexión sobre las herramientas libres para construir mapas en internet, especialmente del proyecto OpenStreetMap, y sus posibilidades para futuros trabajos internacionales coordinados.

Palabras clave: prosodia; entonación; dialectología; mapa.

\section{Abstract}

This paper presents the first "Prosodic Map of Chile", a long-term project aimed at documenting and describing (both phonetically and phonologically) the suprasegmental features of Chilean Spanish. In order to better appreciate the map's reach, a review of currently implemented similar prosodic maps is provided, including AMPER, ATLES and some others. This review considers what particular parameters are studied in each map, closely inspecting what are the foundations, directions and the overall reach of each one of them. The closing section provides a consideration of some freely available software tools designed to build maps, particularly OpenStreetMap, focusing on its potential for future international collaborative efforts.

Keywords: prosody; intonation; dialectology; map. 


\section{Presentación}

A partir del siglo XX, los mapas dialectológicos han tenido un desarrollo relevante tanto desde la perspectiva de la geografía lingüística como de la dialectología (Quesada, 2014). En nuestro país es decisivo el trabajo de Wagner $(1998,2004,2005)$, que proporciona material descriptivo, sobre todo en el plano léxico del español de Chile. Esta era la tendencia de los mapas dialectológicos, hasta hace poco tiempo, los cuales se concentraban exclusivamente en cuestiones léxicas o de fonética segmental. Sin embargo, más recientemente han surgido varias iniciativas que relacionan datos prosódicos con variación geográfica. Las razones de esta irrupción tienen que ver tanto con avances teóricos como tecnológicos.

Algunos de estos desarrollos fueron muy significativos para la fonética acústica y con implicancias notables para los estudios perceptivos. La síntesis PSOLA (Pitch Synchronous Overlap and Add), de fines de los 80 (Charpentier y Stella, 1986), es una herramienta que permite modificar la frecuencia fundamental, o $f_{0}$, sin alterar la velocidad del sonido registrado. Por otra parte, las investigaciones desde el punto de vista experimental y perceptual del IPO (The Institute for Perception Research, Eidenhoven) sugieren categorías analíticas relevantes como por ejemplo la close copy o copia sintetizada indistinguible del original (Hart y otros, 1990), lo que impulsaría la investigación posterior. Estas conceptualizaciones han sido aplicadas en la construcción de mapas prosódicos, en la medida en que se han realizado pruebas perceptivas con la frecuencia fundamental manipulada o bien con audios que son síntesis del tono fundamental y que no tienen información acústica de formantes, con lo cual solo se percibe la entonación. Han sido aportes fundamentales para la indagación experimental de la prosodia ya que han permitido el trabajo con la manipulación de una variable.

Desde el punto de vista fonológico, la perspectiva que más se utiliza actualmente es el modelo métrico autosegmental y su método derivado ToBI (Tone and Break Indices). Este método se ha ido desarrollando progresivamente, y para el caso de la lengua española hay algunas revisiones como las de Face y Prieto (2007) y Estebas-Vilaplana (2009), así como otros trabajos que reúnen el inventario fonológico de algunas variedades del español como los de Hualde y Prieto (2015) y Prieto y Roseano (2010), que han generado resultados de interés, y en los que se incluye un trabajo sobre el español de Chile (Ortiz y otros, 2010: 255-283).

El sistema de notación Sp_ToBI (Spanish Tone and Break Indices) es utilizado por todos los mapas prosódicos que acá se documentan, debido a que se ha tenido el interés de constituir un modelo con criterios de análisis homogéneos, que permita hacer comparaciones fonológicas entre variedades del español y entre lenguas romances. De esta manera, los mapas prosódicos han tenido una importante influencia fonológica que ha permitido desarrollar y complementar el Sp_ToBI, a partir de la inclusión de diferentes variedades. Esto, a su vez, ha permitido que este sistema de notación sea más abarcador, logre reflejar los movimientos tonales de las distintas variedades dialectales y, por tanto, se constituya cada 
vez más como un importante referente para el análisis. Así, las investigaciones que giran en torno a los mapas prosódicos contribuyen al desarrollo, continua discusión y mejoramiento de este modelo de análisis.

Sumado a lo anterior, los avances en procesamiento de datos que permiten agrupar los datos multivariados, tales como los análisis de cluster y otros, han dado un impulso relevante a los estudios que se denominan geoprosodia (véase, por ejemplo, Contini, 1994, 2015; Romano y otros, 2012).

La utilidad de estos mapas y de estos procesamientos es múltiple. La sola descripción de los dialectos ya es en sí un aporte, pero, adicionalmente, pueden tener utilidad pedagógica para, por ejemplo, la enseñanza del español como segunda lengua, para revisar normalidades entonativas ligadas a patologías del habla, para la creación de herramientas en el área de tecnologías del habla con dialectos específicos, entre otros.

\section{Parámetros acústicos de la prosodia}

En la actualidad hay consenso de que los tres parámetros que permiten estudiar la prosodia, desde el punto de vista de la fonética acústica, son la frecuencia fundamental o $f_{0}$, la intensidad y la duración. Estos parámetros acústicos tienen sus correspondientes correlatos articulatorios y perceptivos. Al ser datos medibles y cuantificables, es posible utilizarlos como punto de partida para análisis y aplicaciones implementadas en diferentes soportes.

Los valores correspondientes a cada parámetro se pueden obtener a través de diversos medios. En una aplicación como Praat (Boersma y Weenink, 2015), es posible etiquetar los puntos o segmentos fónicos de interés y obtener de manera automática los valores de los tres parámetros o, incluso, usar algún sistema de etiquetaje automático, como EasyAlign (Goldman, 2011).

Para el estudio de la frecuencia fundamental el procedimiento estándar es el método de autocorrelación, que permite detectar automáticamente momentos periódicos en una señal de habla. Sin embargo, como resultado de la aplicación de este algoritmo de autocorrelación, se generan algunos errores que hacen necesaria una edición y corrección de los valores proporcionados por el algoritmo.

El método de autocorrelación funciona mediante una ventana de análisis que se repite sobrepuesta a intervalos regulares en la señal (recuérdese que un oscilograma es la representación de los valores de amplitud en las muestras del audio). Los valores de la ventana se almacenan y la ventana se desplaza. Si los valores en la nueva posición de la ventana son semejantes a los de una ventana anterior, entonces se encuentra periodicidad en la señal y, por lo mismo, valores para la frecuencia fundamental. 
En cuanto al análisis del parámetro de intensidad, para convertir los valores de amplitud de una señal en dB se utiliza un método de RMS (root mean square), con lo cual se obtienen valores de intensidad de la señal. La interpretación del valor en dB de cada punto debe hacerse en relación con el de otro de la misma señal.

La figura 1 muestra la parte superior del oscilograma y la curva de intensidad correspondiente. Obsérvese que la curva de intensidad es semejante en grado alto al perfil superior del oscilograma. La figura 2, por su parte, muestra una curva de intensidad y la curva sincrónica de las variaciones de la frecuencia fundamental una vez corregidos los errores.

\section{FIGURA 1}

Perfil de oscilograma (valores de amplitud a la derecha, en pascales) y curva de intensidad superpuesta (valores en $\mathrm{dB}$ a la izquierda)

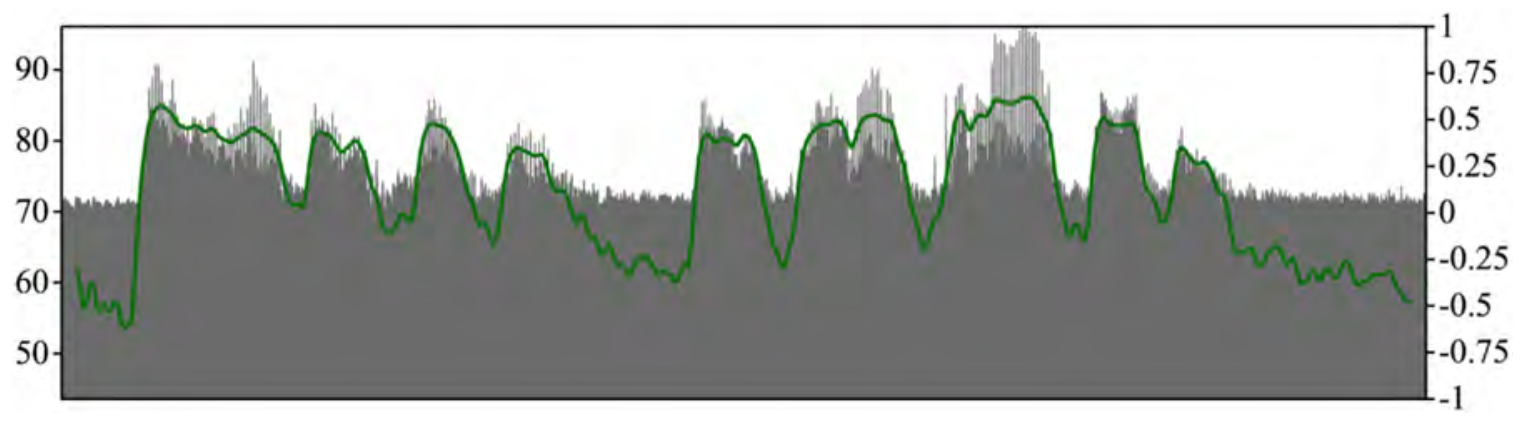

\section{FIGURA 2}

Curva de intensidad y curva de $f_{0}$ de una misma emisión

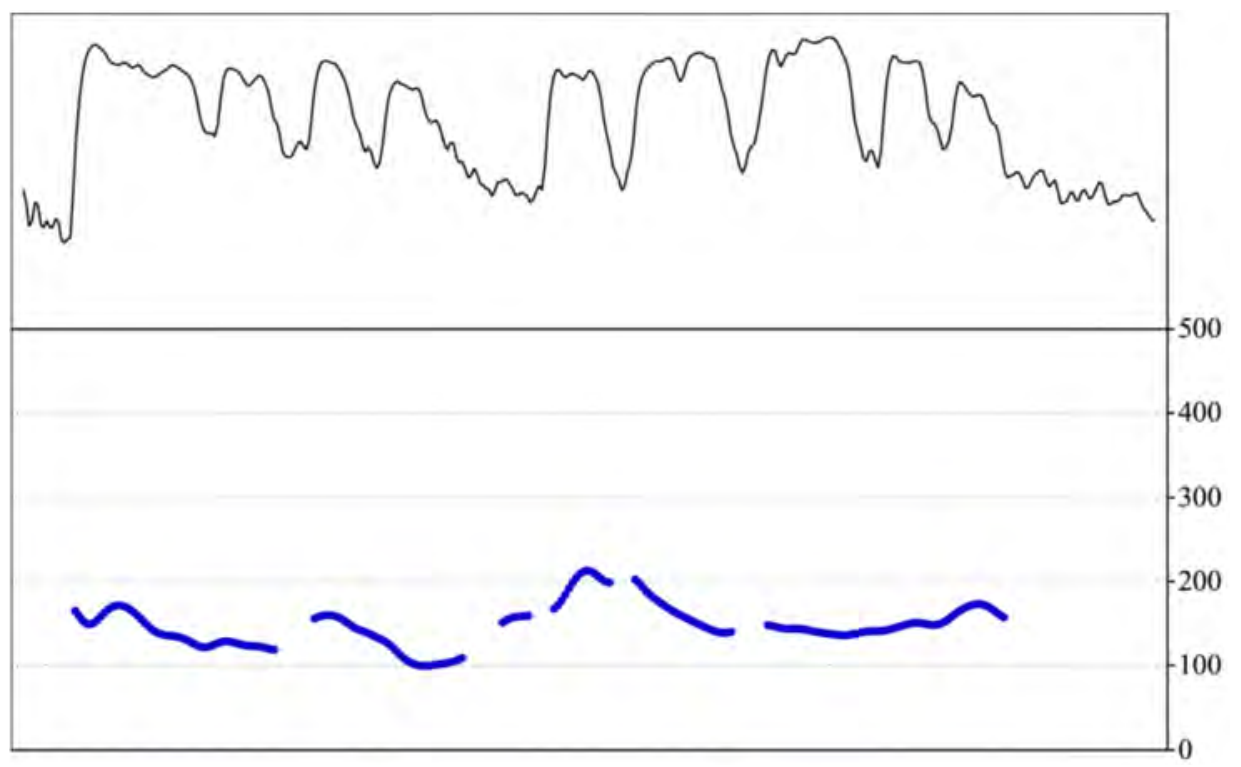




\section{FIGURA 3}

Valores de pitch y estilización a partir de los puntos centrales de las vocales de la frase "Oiga, Panchito ¿Cuánto vale el kilo de papas?"

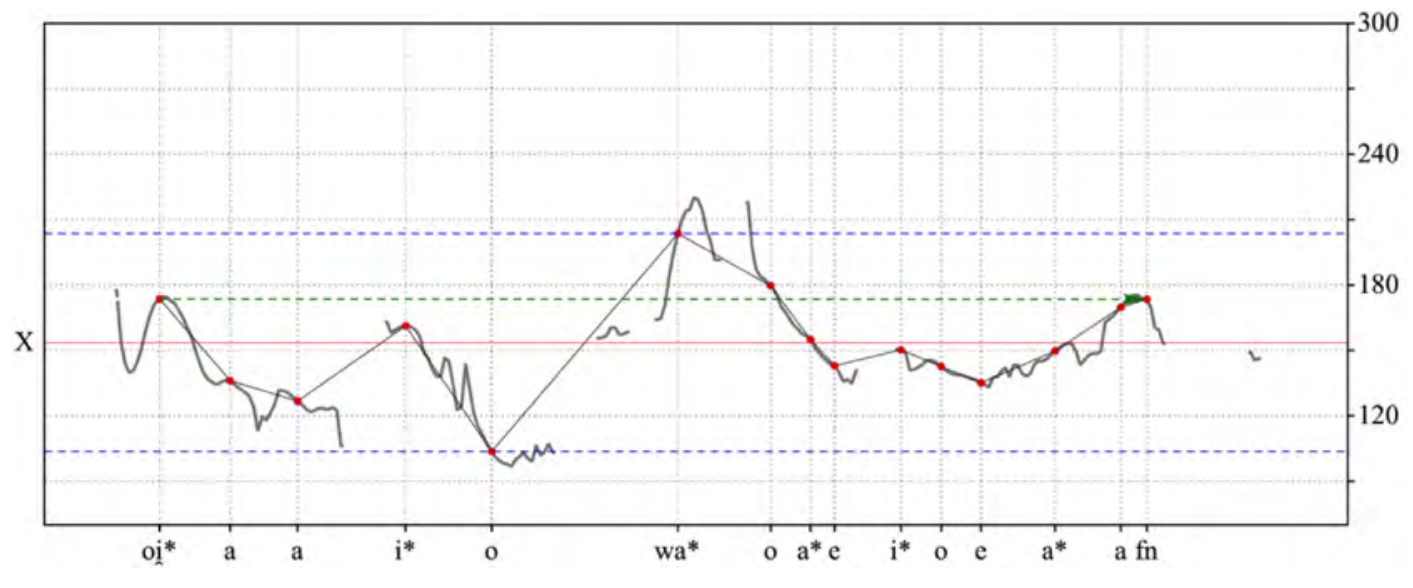

Para efectos de normalizar los datos obtenidos en pruebas de producción o para construir estímulos para instrumentos de percepción se utiliza la conversión a semitonos (st). Esta conversión requiere un punto de referencia, que puede ser $1 \mathrm{~Hz}, 100 \mathrm{~Hz}, 200 \mathrm{~Hz}$ o bien el promedio en $\mathrm{Hz}$ del enunciado que se analiza. En la figura 3 se muestra un ejemplo de normalización de datos, que incluye la curva original de frecuencia fundamental en $\mathrm{Hz}$ y los puntos en los centros vocálicos con los cuales se construye una curva estilizada. Se señalan también los valores máximos y mínimos y el promedio en $\mathrm{Hz}$.

Ahora bien, en la figura 4 se muestra la curva correspondiente a la conversión de los valores de cada uno de los puntos etiquetados a diferencias en semitonos referidos al promedio de la emisión. Como se puede observar, la forma de la curva es semejante, pero esta normalización tiene la ventaja de que las variaciones son comparables, por ejemplo, entre hombres y mujeres.

\section{FIGURA 4}

Valores de la figura 3 normalizados en st referidos al promedio de la emisión

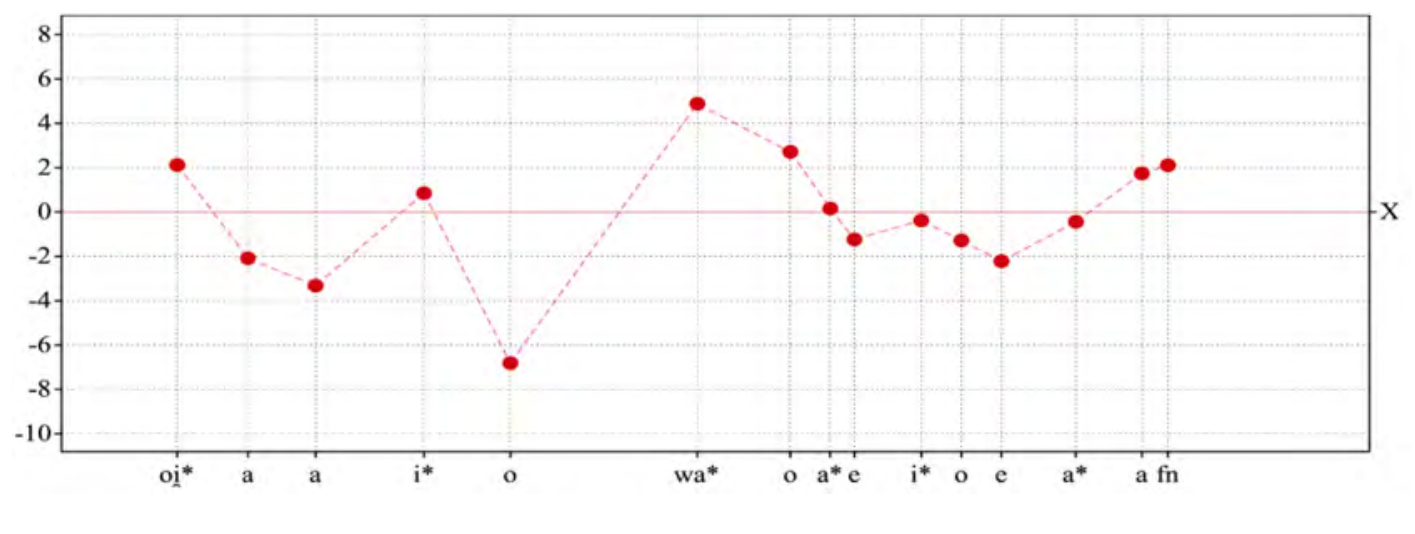


La formulación de la síntesis Pitch Synchronous Overlap and Add (PSOLA) abrió la puerta para investigaciones perceptivas al permitir presentar estímulos modificados solo en su prosodia, es decir, conservando la información segmental. Adicionalmente, hoy en día es posible crear estímulos que sean una buena réplica del tono glotal sin información distintiva de los formantes vocálicos ni de las consonantes sonoras (semejante a la que se puede obtener con un electroglotógrafo). También es posible usar estos objetos sonoros en pruebas de percepción. La tecnología permite incluso sustituir la curva de frecuencia fundamental de una frase por la de otra diferente, o bien alterarla para convertirla en una variable controlada de la investigación.

Las investigaciones del grupo IPO sobre los umbrales perceptivos en la discriminación tonal para efectos del lenguaje (alrededor de 2 st) permiten la estilización de la curva tonal, y se crea así la copia estrecha (Hart y otros, 1990). Una vez probado que perceptivamente es indistinguible del original, se trabaja con esos valores que permiten observar movimientos tonales simplificados. La estrategia argumentativa es que si se respetan los umbrales perceptivos de diferencias lingüísticas y la emisión con curva simplificada es indistinguible al oído del enunciado original, entonces se tiene una representación totalmente equivalente, con todas las ventajas en la investigación que ofrece un objeto más simple. La estilización permite, así, considerar los movimientos frecuenciales relevantes en el plano de la audición y de la percepción del tono ya que no toda variación en Hz es percibida como un cambio de altura tonal.

Desde el punto de vista fonológico, uno de los métodos más extendidos actualmente para el análisis de la entonación es el modelo métrico autosegmental, que tiene sus bases en la tesis doctoral de Pierrhumbert (1980). Específicamente para el español se ha creado el sistema de notación Sp_ToBI (Spanish Tone and Break Indices). Dentro de este modelo se describen los contornos de los acentos tonales, asociados a las sílabas prominentes, y los tonos de juntura alineados con las fronteras o cesuras prosódicas (Beckman y otros, 2002; Estebas-Vilaplana y Prieto, 2008; Hualde y Prieto, 2015).

Para describir la entonación desde este enfoque se utilizan tonos monotonales, como H* (High) o $L^{*}($ Low $)$, y tonos bitonales ascendentes y descendentes $\left(L^{*}+H, L+H^{*}, H+L^{*} \ldots\right)$, además de otras marcas como asterisco (“*”) para diferenciar los acentos tonales y porcentaje (“\%”) para identificar los acentos de frontera; ángulo "<", para indicar el desplazamiento del pico tonal (adoptado a partir de Hualde y Prieto, 2015); “i” (“upstep”) para sugerir que hay un escalonamiento ascendente o "!” (“downstep") un escalonamiento descendente, evidenciando, respectivamente, una ampliación o reducción sistemática en la altura tonal (Estebas-Vilaplana y Prieto, 2008). Este es el marco teórico metodológico más adoptado en los estudios del español y en los mapas que aquí se comentan.

\section{Los proyectos internacionales para el mundo hispánico}

Actualmente, hay dos grandes proyectos internacionales que reúnen la mayor cantidad de trabajos relacionados con el español. Por una parte, está AMPER (Atlas Multimedia del Espacio 
Románico), de orientación fonética, y, por otra parte, está el ATLES (Atlas de la entonación del español), que tiene una tendencia más bien fonológica. Además de estos proyectos, hay otras investigaciones de alcance nacional que van en la misma línea de análisis y pretenden caracterizar y analizar el español hablado en países o regiones particulares. Así, entre otros, está el Corpus oral del español de México (COEM, Martín Butragueño y otros, en preparación), el Mapa prosódico de Antioquia-Colombia (Muñoz, en preparación) y, el objeto principal de este artículo, el Mapa prosódico de Chile (Román, 2013-2016). En general, estos mapas prosódicos han propendido a hacer análisis mixtos entre la fonética y la fonología, presentando de una manera holística la variación geolectal del fenómeno de la entonación.

\subsection{AMPER}

El proyecto AMPER es uno de los mapas prosódicos multimedia interlingüísticos, ya que contiene datos del sardo, italiano, francés, rumano, portugués, español (múltiples dialectos), catalán, gallego y otros. El propósito de construir un atlas prosódico que contenga todas las lenguas romances es lograr hacer comparaciones de naturaleza geoprosódica o dialectológica. Para esto, el proyecto utiliza un informante de cada sexo para cada punto estudiado, que sea representativo de su dialecto.

Las características de los corpus están descritas en Fernández Planas (2005) y en Martínez Celdrán y Fernández Planas (2005). El material que más se ha trabajado hasta el momento es el Ilamado corpus fijo, que consta, en el caso del español, de 63 oraciones (que combinan palabras oxítonas, paroxítonas y proparoxítonas en el sintagma nominal y en el complemento verbal) y dos modalidades (enunciativa e interrogativa). Cada oración es repetida tres veces por el informante, con lo que se obtienen 189 frases por informante y 378 enunciados por cada punto de análisis. Típicamente, se miden los tres parámetros acústicos estándar de la prosodia en tres puntos de cada segmento vocálico de una frase determinada. Con ello, se obtiene una síntesis a partir de los promedios por sílaba de los tres parámetros, permitiendo analizar el comportamiento de la prosodia de una manera detallada dentro de cada variedad de habla.

El entorno analítico es, en principio, Matlab — aunque existe también una rutina equivalente en Praat (Rilliard, s. f.) - L Las oraciones del corpus fijo fueron construidas con preponderancia de consonantes sordas para facilitar, por contraste, la identificación de las vocales (que, como se sabe, son sonoras). Los audios se limpian de ruido y se amplifican para facilitar el análisis. Las vocales se delimitan y, automáticamente, la rutina marca tres puntos en cada una de ellas (inicio, centro y final). Con estas marcas se obtienen los tres valores correspondientes a cada parámetro, en $\mathrm{Hz}$, ms y dB. Los valores en $\mathrm{Hz}$ pueden ser corregidos manualmente por el investigador. La rutina crea archivos con datos numéricos de los tres parámetros y una simulación del tono glotal de cada emisión. Es interesante que dentro de este análisis se genera una síntesis con los promedios (de los tres parámetros) de las tres emisiones de cada una de las frases del corpus. Este material ha sido utilizado en pruebas perceptivas (véase, entre otros, Otero y otros, 2016). 
Si bien la orientación original de este proyecto era principalmente fonética, varios trabajos han sido complementados con una interpretación fonológica de los datos e incluso con herramientas para automatizar el etiquetaje fonológico de la entonación (Elvira-García y otros, 2016).

\subsection{ATLES}

El proyecto hispánico ATLES, derivado del proyecto mayor IARI (Interactive Atlas of Romance Intonation), es un mapa interactivo que presenta de manera sistemática audios y videos para el estudio de la variación geoprosódica. Contiene material de dialectos americanos, como por ejemplo el mexicano, el centroamericano, el caribeño, el amazónico, el andino y dialectos del Cono Sur, y materiales de dialectos europeos como el castellano septentrional, el castellano centro meridional, el andaluz, el canario y algunas zonas bilingües con el catalán, el euskera, el aragonés, el gallego, el asturleonés y el occitano.

El corpus disponible se basa en diferentes tareas: DCT, Map-Task y un fragmento de habla espontánea. Los sujetos entrevistados para las dos primeras tareas fueron mujeres de entre 20 y 35 años, con estudios de grado medio o superior. En la entrevista, en cambio, hay hombres y mujeres, mayores de 60 años de edad. Lingüísticamente, las frases elicitadas corresponden a diferentes tipos de enunciados: frases declarativas, interrogativas absolutas, interrogativas parciales, interrogativas reiterativas, ruegos, órdenes y vocativos.

Uno de los objetivos principales de este proyecto es proponer un sistema de etiquetado tonal ToBI para diferentes lenguas, entre ellas el español, a partir del análisis de datos de diferentes variedades del español de América y de Europa (Prieto y Roseano, 2009-2013). Como ya se mencionó, el hecho de que gran cantidad de investigaciones entonativas se realicen bajo el mismo modelo de análisis permite que cada vez el sistema sea complementado y fortalecido con los fenómenos registrados en cada variedad de habla. El análisis de las frases consiste en describir la curva melódica en términos de las variaciones de la frecuencia fundamental y el etiquetaje prosódico ToBI (Prieto y Roseano (eds.), 2010). De esta manera, se permite también hacer comparaciones entre respuestas de diferentes dialectos.

\subsection{El mapa prosódico de Chile}

El proyecto Fondecyt Mapa prosódico de Chile es tributario de los dos grandes proyectos mencionados anteriormente. En este proyecto se recoge material de 8 puntos del país, desde Arica hasta Punta Arenas, y se trabaja con varios tipos de muestras, que incluyen habla de diferentes grados de formalidad.

\subsubsection{Corpus}

El corpus recogido para el Mapa prosódico de Chile se compone de siete tareas. La primera de ellas es la lectura de frases de diferente modalidad oracional, tales como "Velozmente reco- 
rrió toda la cancha” o “¿Le gusta el pan amasado?”. En esta misma línea, la segunda tarea se compone de lectura de textos cortos, como "El pantalón nunca le quedó bien. En realidad, el pantalón no estaba bien hecho porque el sastre — que en realidad, no era muy profesionalnunca quiso hacerlo con calma y dedicación (...)”.

La tercera tarea es un instrumento de retextualización de historias en la que los colaboradores debían leer un texto y luego narrarlo con sus propias palabras. Esta tarea permitió obtener muestras de habla con un bajo nivel de formalidad, lo que redundó en la obtención de datos con una relativa espontaneidad de los colaboradores, que permitirá hacer análisis de habla más cercana al uso real. Un ejemplo de texto presentado es el siguiente:

Josefa y Leonardo decidieron casarse. Josefa es muy alta, y Leonardo es bajito. La ceremonia fue muy bonita y la fiesta estuvo muy muy buena. Todos los invitados lo pasaron muy bien. Hicieron el matrimonio en una casa muy grande, antigua y muy bien decorada.

En medio de la ceremonia, comenzó a llover. La lluvia fue tanta que al final los invitados se tuvieron que quedar toda la noche en la casa.

Al otro día, los novios aprovecharon todo lo que había sobrado de la comida de la noche anterior para hacer un gran desayuno con sus amigos y parientes.

El mapa prosódico de Chile, a diferencia de los demás mapas presentados hasta ahora, incluye dos tareas basadas en imágenes: descripción y enumeración. En la primera, el informante debía contar, con detalles, lo observado en diferentes imágenes, como por ejemplo la presentada en la figura 5, y en la segunda tarea debía enumerar los objetos observados, como los expuestos en la figura 6, antecediendo la frase: "Acá veo".

\section{FIGURA 5}

Ejemplo de tarea de descripción de imágenes

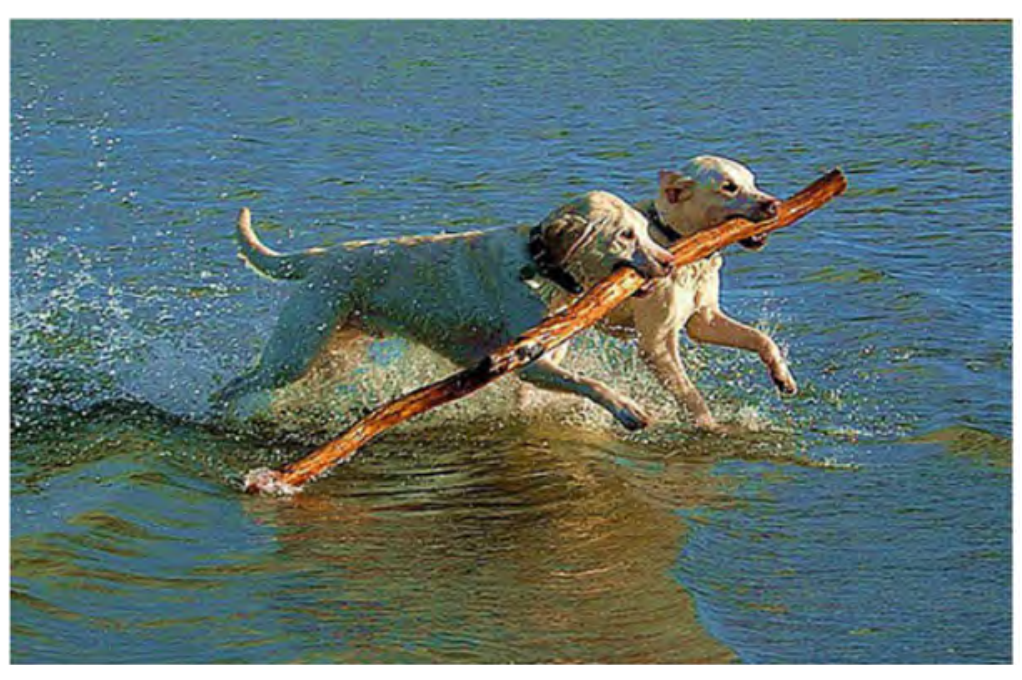




\section{FIGURA 6}

Ejemplo de tarea de enumeración de imágenes
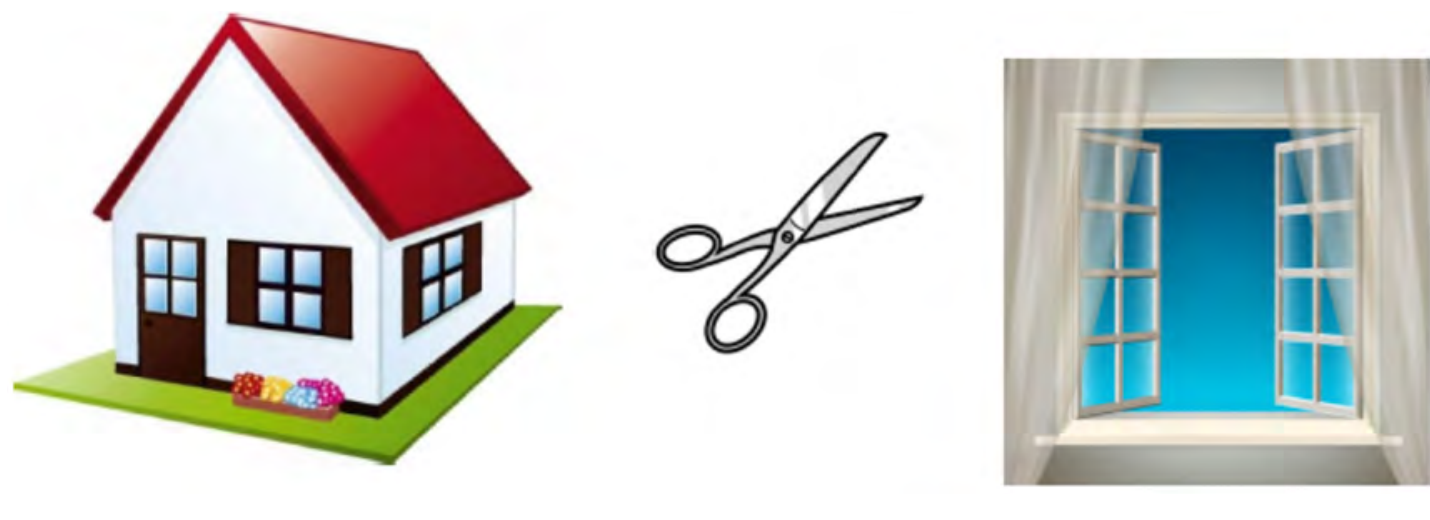

La sexta tarea utilizada en el Mapa prosódico de Chile es el conocido DCT (Discourse-completion task) (Blum-Kulka y Olshtain, 1984). Sin embargo, a diferencia de como se aplica tradicionalmente, el informante no respondía espontáneamente, sino que, dentro de este proyecto, se le daba al informante la frase con la cual debía responder a la situación presentada. Este método permitió obtener las mismas frases para todos los informantes, con el agregado positivo de que fueron producidas con un menor nivel de formalidad, respecto a la lectura de frases.

\section{Ud. Tiene que decir:}

\section{¡Por ningún motivo!}

La situación es la siguiente:

Un amigo llamado Claudio le debe dinero. Hace un año le pidió \$500.000 prestados y nunca se los devolvió. Se encuentra con él y le pide la misma cantidad de dinero.

Ud. sabe que no devuelve la plata entonces le dice:

\section{¡Por ningún motivo!}

Finalmente, la séptima tarea utilizada dentro del Mapa prosódico de Chile es una conversación inicial y otra final, entre el entrevistado y el examinador, en las que se dialoga sobre temas de interés para el primero. Esta tarea ha sido una constante dentro de todos los mapas prosódicos, debido a que es una necesidad imperante, aunque poco trabajada, analizar el habla en el estado más natural y espontáneo posible.

Los fenómenos lingüísticos utilizados en el diseño de los textos, las oraciones y los DCT son, entre otros, el choque acentual, los vocativos, las frases explicativas, las modalidades interrogativas, enunciativas, exclamativas y las peticiones con distinto grado de cortesía. También se incluyeron algunas frases del proyecto AMPER del español (algunas adaptadas al léxico de Chile) para posibilitar comparaciones futuras con otros dialectos. 
Desde el punto de vista metodológico, la lectura de textos fue el instrumento que entregó resultados más disímiles, debido a que las competencias lectoras de los participantes eran muy desiguales. La ventaja de las muestras estructuradas es la posibilidad de una comparación clara, gracias al control de las variables. Sin embargo, existen también desventajas, como la falta de naturalidad, siempre deseable en estudios del lenguaje. El DCT resultó muy productivo, tal como lo fueron la conversación, la enumeración y la retextualización.

\subsubsection{Participantes}

Los participantes en el Mapa prosódico de Chile fueron 160 sujetos, un número sin precedentes en los estudios prosódicos nacionales y, posiblemente, internacionales. Esta gran cantidad de sujetos permitió tener una amplia cobertura geográfica de Chile y permitió seleccionar a los participantes de acuerdo a las variables sociales de sexo (hombre, mujer) y zona (rural, urbana). Además de ello, los informantes fueron personas sin formación universitaria que supiesen leer, que hubiesen nacido en el lugar, que hubiesen vivido la gran mayoría del tiempo en la zona y que no presentaran trastornos cognitivos evidentes, ni trastornos del habla. Las ciudades y los puntos rurales donde se llevaron a cabo las entrevistas se resumen en la tabla 1. En cada uno de estos puntos se registró a cinco hombres y a cinco mujeres pertenecientes a la zona urbana y a otros cinco hombres y otras cinco mujeres de las localidades rurales.

\section{TABLA 1}

Puntos de encuesta urbanos y rurales del Mapa prosódico de Chile

\begin{tabular}{llll} 
& ZONA & URBANO & RURAL \\
1. & Arica & Arica & Putre \\
\hline 2. & Antofagasta & Antofagasta & San Pedro de Atacama \\
\hline 3. & La Serena & La Serena & Las Rojas \\
\hline 4. & Santiago & Conchalí & Chiñihue \\
\hline 5. & Concepción & Concepción & Halqui \\
\hline 6. & Temuco & Temuco & Niagara \\
\hline 7. & Chiloé & Castro & Pilque \\
& & & Nercón \\
\hline 8. & Punta Arenas & Punta Arenas & Dorotea \\
& & & Puerto Natales \\
\hline
\end{tabular}

\subsubsection{Análisis}

Las indagaciones realizadas en el proyecto se encuentran en desarrollo y los resultados ya han entregado conclusiones relevantes, como por ejemplo el habla ascendente registrada en 
la zona urbana y rural de Chiloé, específicamente en oraciones aseverativas finales con foco amplio (Muñoz y otros, 2017).

Desde la perspectiva del análisis de $f_{0}$, resultó especialmente relevante el rango, es decir, la diferencia entre máximos y mínimos expresada en st, referido al promedio en $\mathrm{Hz}$ del enunciado. La alineación del pico de $f_{0}$ con la sílaba tónica, que puede estar ajustada a la sílaba o, como muchas veces sucede, desplazado a la derecha. La acentuación oracional se pone en relieve por la diferencia en st entre, por una parte, los puntos de más bajos valores anterior y posterior y también por la diferencia entre los valores de picos frecuenciales más altos en una emisión. También parece ser interesante la pendiente de st en el tiempo entre el punto de inicio de la $f_{0}$ y el último rastro de la misma.

Como ya se adelantó en el apartado anterior, dada la naturaleza del material recogido en este mapa prosódico, se puede investigar también el choque acentual, la prosodia de vocativos, de frases intercaladas y varios otros fenómenos que se tuvieron en cuenta al momento del diseño de los instrumentos. Desde el punto de vista del análisis de los parámetros, se puede estudiar especialmente la frecuencia fundamental, pero también su interacción con la intensidad y la duración para determinados esquemas prosódicos.

Por último, en la tabla 2 se condensan las características de los principales mapas prosódicos que se han referido en esta reflexión teórico-metodológica (véase la tabla en la página siguiente). Por tanto, se ha considerado AMPER (Atlas multimedia de prosodia del espacio románico, http:// stel.ub.edu/labfon/amper/cast/index_internacional.html), IARI (Interactive Atlas of Romance Intonation, http://prosodia.upf.edu/iari/), ATLES (Atlas de la entonación del español, http://prosodia.upf.edu/atlasentonacion/), COEM (Corpus oral del español de México, https://lef.colmex. mx/corpus_oral_del_espanol_de_mexico.html), Mapa prosódico de Antioquia-Colombia y, naturalmente, Mapa prosódico de Chile (https://fonetica.usach.cl/mapa-de-la-prosodia-de-chile).

\section{Perspectivas dialectométricas}

Uno de los grandes problemas a los que se ha enfrentado la dialectología tradicional es la manera de decidir qué criterios considerar para hacer una taxonomía de los dialectos, por lo que una de las soluciones clásicas ha sido el análisis cualitativo. Sin embargo, esto conlleva varios problemas. En primer lugar, la flexibilidad de los criterios para la clasificación dialectal da entrada a la subjetividad del investigador, quien se ve influido por su propio conocimiento lingüístico y su percepción dialectal. En segundo lugar, las áreas de trazos lingüísticos no siempre tienen una distribución geográficamente compacta, lo que dificulta el procesamien-

1 La misma diferencia conceptual entre dialecto y lengua ha sido sometida a cuestionamiento varias veces. 


\section{TABLA 2}

Comparación de mapas prosódicos del mundo hispánico

\begin{tabular}{|c|c|c|c|c|c|c|}
\hline MAPA & $\begin{array}{l}\text { PAIS } 0 \\
\text { ZONA }\end{array}$ & $\begin{array}{l}\text { LENGUAS / } \\
\text { DIALECTOS }\end{array}$ & $\begin{array}{l}\text { NoDE } \\
\text { INFORMANTES } \\
\text { POR ZONA }\end{array}$ & $\begin{array}{l}\text { VARIABLES } \\
\text { SOCIALES }\end{array}$ & $\begin{array}{l}\text { CORPUS } \\
\text { UTILIZADO }\end{array}$ & $\begin{array}{l}\text { PARÁMETROS } \\
\text { ANALIZADOS }\end{array}$ \\
\hline AMPER & $\begin{array}{l}\text { España } \\
\text { Chile } \\
\text { Argentina } \\
\text { México } \\
\text { Venezuela } \\
\text { Cuba } \\
\text { Bolivia } \\
\text { Guatemala } \\
\text { Colombia } \\
\text { Ecuador } \\
\text { Estados } \\
\text { Unidos } \\
\text { Perú } \\
\text { Paraguay } \\
\text { Uruguay } \\
\text { República } \\
\text { Dominicana } \\
\text { Honduras }\end{array}$ & $\begin{array}{l}\text { Sardo } \\
\text { Italiano } \\
\text { Friulano } \\
\text { Francés } \\
\text { Rumano } \\
\text { Portugués } \\
\text { Catalán } \\
\text { Gallego } \\
\text { Español } \\
\text { (múltiples } \\
\text { dialectos) }\end{array}$ & 4 & $\begin{array}{l}\text { Sexo } \\
\text { (femenino- } \\
\text { masculino) } \\
\text { Zona } \\
\text { (urbana-rural) } \\
\text { Edad (25-55 } \\
\text { años) } \\
\text { Nivel } \\
\text { escolaridad } \\
\text { bajo (sin } \\
\text { estudios } \\
\text { superiores) }\end{array}$ & $\begin{array}{l}\text { Lectura de frases } \\
\text { Maptask } \\
\text { DCT } \\
\text { Conversación }\end{array}$ & $\begin{array}{l}f_{0} \\
\text { Duración (ms) } \\
\text { Intensidad (dB) }\end{array}$ \\
\hline $\begin{array}{l}\text { IARI y } \\
\text { ATLES }\end{array}$ & $\begin{array}{l}\text { España } \\
\text { Venezuela } \\
\text { Ecuador } \\
\text { Perú } \\
\text { Colombia } \\
\text { Argentina } \\
\text { Chile } \\
\text { México } \\
\text { Puerto Rico } \\
\text { República } \\
\text { Dominicana }\end{array}$ & $\begin{array}{l}\text { Portugués } \\
\text { Español } \\
\text { Francés }\end{array}$ & 2 & $\begin{array}{l}\text { Sexo } \\
\text { (femenino- } \\
\text { masculino) } \\
\text { Edad }\end{array}$ & $\begin{array}{l}\text { Encuesta de } \\
\text { situaciones } \\
\text { Maptask } \\
\text { Entrevista } \\
\text { en video }\end{array}$ & $\begin{array}{l}\text { Tonos } \\
\text { Configuraciones } \\
\text { nucleares }\end{array}$ \\
\hline COEM & México & $\begin{array}{l}\text { Español de } \\
\text { México }\end{array}$ & Entre 12 y 20 & $\begin{array}{l}\text { Sexo } \\
\text { Edad (tres } \\
\text { grupos) } \\
\text { Nivel de } \\
\text { estudios } \\
\text { (tres grupos) }\end{array}$ & $\begin{array}{l}\text { Enunciados } \\
\text { leídos } \\
\text { Palabras aisladas } \\
\text { DCT } \\
\text { Maptask } \\
\text { Entrevista } \\
\text { Cuestionario } \\
\text { sociológico } \\
\text { detallado }\end{array}$ & $\begin{array}{l}f_{0}(\mathrm{~Hz}, \mathrm{st}) \\
\text { Duración (ms) } \\
\text { Intensidad } \\
\text { (dB) Sp_ToBI } \\
\text { adaptado }\end{array}$ \\
\hline $\begin{array}{l}\text { Mapa } \\
\text { prosódico } \\
\text { de } \\
\text { Antioquia- } \\
\text { Colombia }\end{array}$ & Colombia & $\begin{array}{l}\text { Español de } \\
\text { Colombia }\end{array}$ & 24 & $\begin{array}{l}\text { Sexo } \\
\text { Edad } \\
\text { Municipio } \\
\text { Estrato } \\
\text { sociocultural }\end{array}$ & $\begin{array}{l}\text { Lectura de frases } \\
\text { Lectura con } \\
\text { contexto } \\
\text { DCT } \\
\text { Lectura de } \\
\text { imágenes con } \\
\text { diferentes } \\
\text { estructuras } \\
\text { informativas } \\
\text { Conversación }\end{array}$ & $\begin{array}{l}f_{0}(\mathrm{~Hz}, \mathrm{st}) \\
\text { Duración (ms) } \\
\text { Intensidad (dB) } \\
\text { Tonos }\end{array}$ \\
\hline
\end{tabular}




\begin{tabular}{|c|c|c|c|c|c|c|}
\hline $\begin{array}{l}\text { Mapa } \\
\text { prosódico } \\
\text { de Chile }\end{array}$ & Chile & $\begin{array}{l}\text { Español } \\
\text { de Chile }\end{array}$ & 10 & $\begin{array}{l}\text { Sexo } \\
\text { (femenino- } \\
\text { masculino) } \\
\text { Zona } \\
\text { (urbana-rural) }\end{array}$ & $\begin{array}{l}\text { Lectura de frases } \\
\text { Lectura de } \\
\text { textos cortos } \\
\text { Retextualización } \\
\text { Descripción } \\
\text { de imágenes } \\
\text { Enumeración } \\
\text { de imágenes } \\
\text { DCT } \\
\text { Conversación }\end{array}$ & $\begin{array}{l}f_{0}(\mathrm{~Hz}, \mathrm{st}) \text { : } \\
\text { rango tonal, } \\
\text { declinación, } \\
\text { distancia en st } \\
\text { de cada vocal } \\
\text { al promedio } \\
\text { de frase } \\
\text { Duración (ms) } \\
\text { Velocidad } \\
\text { de habla } \\
\text { Intensidad (dB) } \\
\text { Tonos }\end{array}$ \\
\hline
\end{tabular}

to y análisis de fenómenos ampliamente distribuidos. En tercer lugar, la dialectología se ha caracterizado por tener grandes cantidades de datos, especialmente de atlas etnográficos, que son más difíciles de procesar a través de esta metodología cualitativa. Algunos ejemplos de estos atlas son: Atlas Lingüístico de la Península Ibérica (ALPI), Atlas Lingüístico y Etnográfico de Andalucía (ALEA, 1961-1973), Atlas Lingüístico y Etnográfico de Aragón, Navarra y la Rioja (ALEANR, 1979-1983), Atlas Lingüístico y Etnográfico de Colombia (ALEC, 1982), ALESUCh (Atlas lingüístico-etnográfico del Sur de Chile, 1973), Atlas Lingüístico de la Península Ibérica (ALPI, 1996-2009), Atlas Lingüístico de México (ALMEX, 1990), entre otros. Cabe decir que los estudios prosódicos, indudablemente, contribuirán a reorientar las fronteras geolingüísticas que se han trazado tradicionalmente.

Ante estas dificultades, la dialectometría se configura como una necesidad teórica, práctica y metodológica de la dialectología. Es una alianza entre la geolingüística y la taxonomía numérica como disciplina matemática (Goebl, 1981) que permite un análisis cuantitativo y especializado de los dialectos. De esta manera, la dialectometría tiene una naturaleza holística dado que permite establecer clasificaciones de sistemas dialectales y hacer una representación mejorada de la cartografía dialectal.

Los atlas que han servido como base de datos para los primeros estudios dialectométricos no contienen datos prosódicos. Sin embargo, sí se han creado otros mapas y bases de datos en las que se recoge variación diatópica de la prosodia. Este crecimiento de información ha obligado a los investigadores a pensar en métodos estadísticos que permitan el procesamiento de los datos. En este sentido hay diferentes aplicaciones que facilitan la tarea, como por ejemplo Gabmap, DiaTech, StatDistances, Calcu-Dista, ProDis y Ferramenta informática para a análise dialectométrica.

Finalmente, combinando librerías de proyección cartográfica (como Leaflet.js) y plataformas que ofrecen imágenes para generar mapas (como las de OpenStreetMap), es posible proyectar todo tipo de información sobre un mapa con el nivel de detalle que se requiera, y ofreciéndole al usuario la posibilidad de ajustar la información que se necesita. 
En el Mapa prosódico de Chile, se desarrolló una aplicación que permite seleccionar una de las zonas investigadas, y escuchar ya sea el audio de una frase o bien el tono sintético de la frecuencia fundamental y ver los gráficos disponibles para un ejemplo de cada una de las pruebas realizadas. Se presenta una de las posibilidades en la figura 7.

\section{FIGURA 7}

Ejemplo de una presentación en el mapa prosódico con audición de frase y tono sintético

\section{Mapa prosódico \\ Selecciona una zona: \\ \begin{tabular}{l|l|l|l|l|l|l|l|l}
1 & 2 & 3 & 4 & 5 & 6 & 7 & 8 & $x$
\end{tabular}}

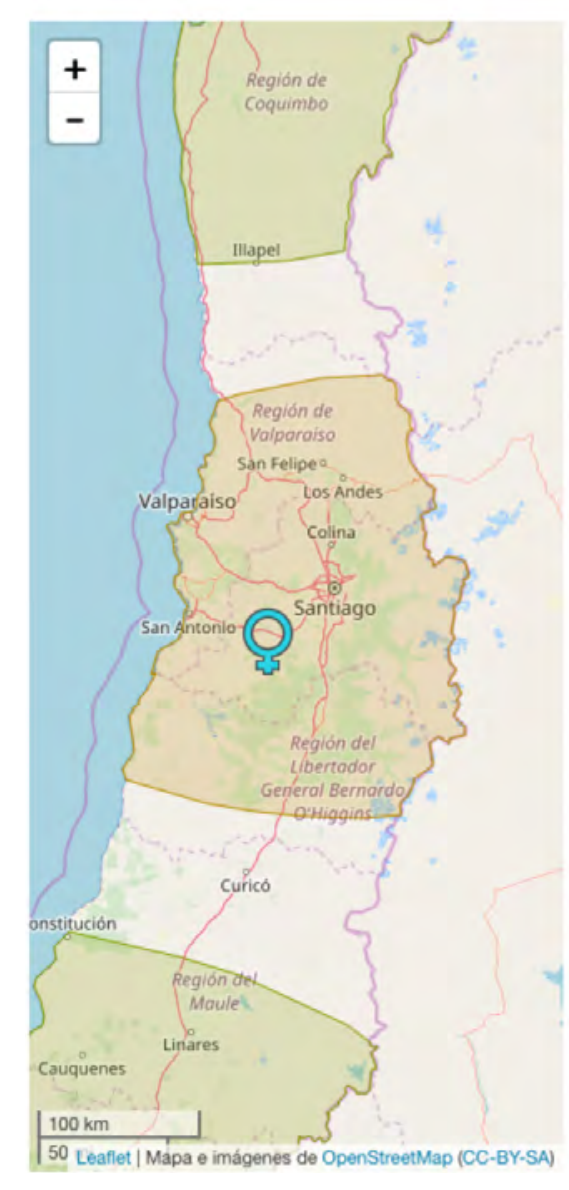

\section{Zona 4}

Completación de discurso 0 urbana 0 Mujer

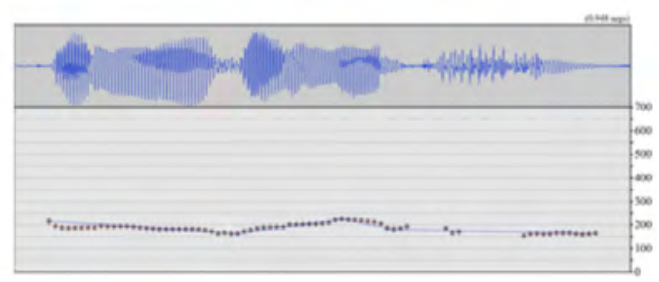

Reproducir grabación

Reproducir tono

\section{Consideraciones finales}

Este mapa prosódico pretende ser un aporte que se relacione con las demás investigaciones de otros países y que permita el desarrollo de una descripción hispanoamericana más global, dado que existen ya varias iniciativas, tal como se ha mencionado anteriormente, y con recursos computacionales homólogos. 
El mapa prosódico de Chile sirve también como exposición de diferencias dialectales que, en un país altamente centralizado y segregado socialmente, como Chile, tiene una función de reivindicación de hablas locales tanto rurales como urbanas.

Por otra parte, cuando se enseña español como segunda lengua, la falta de materiales propios hace que muchas veces se tenga que recurrir a herramientas basadas en hablas de otros países. Esta es una oportunidad para escuchar variedades del español de Chile acompañadas de su descripción técnica.

Actualmente, la investigación prosódica aporta información relevante en el procesamiento del lenguaje natural, lo que tiene aplicaciones tecnológicas que necesariamente deben considerar las especificidades de cada lengua y de cada dialecto. En este sentido, la información de rasgos prosódicos tendrá implementaciones tanto en la producción de habla sintética como en la programación de la interpretación lingüística de señales.

Las proyecciones de un trabajo colaborativo internacional y del trabajo interdisciplinario son inmensas si se tiene en cuenta que, por una parte, los avances computacionales se producen a una velocidad muy grande $y$, al mismo tiempo, las comunidades locales resultan ser cada vez más relevantes en términos de sus patrimonios culturales, y uno de ellos, sin duda, es la prosodia particular que nos diferencia y nos identifica.

\section{Bibliografía citada}

BeCKman, Mary, y otros, 2002: "Intonation across Spanish in the Tones and Break Indices framework", Probus 14, 9-36.

Blum-KulKa, Shoshana, y Elite OLSHTAIN, 1984: "Requests and apologies: A cross-cultural study of speech act realization patterns (CCSARP)", Applied Linguistics 5, 196-213.

Boersma y WeEnink, 2015: Praat: doing phonetics by computer [programa computacional, obtenido de http://www.praat.org/].

Charpentier, F., y M. Stella, 1986: "Diphone synthesis using an overlap-add technique for speech waveforms concatenation", Acoustics, Speech, and Signal Processing, IEEE International Conference on ICASSP'86 11, 2015-2018.

ContinI, Michael, 1994: "Un projet européen de Géolinguistique: l'Atlas Linguistique Roman” en Pilar García Mouton (ed.): Geolingüística. Trabajos europeos, Madrid: Biblioteca de Filología Hispánica del C.S.I.C., 97-110.

ContinI, Michel, 2015: "Analyse contrastive de la prosodie dans les langues romanes: un bilan de l'Atlas Multimédia Prosodique de l'Espace Roman et son élargissement à de nouvelles ap- 
proches posibles", conferencia inaugural del Colóquio Internacional de Geoprosódia do Português e do Galego, Université d’Aveiro (Portugal), Juin 2015.

Elvira-García, Wendy, y otros, 2016: "A tool for automatic transcription of intonation: Eti-ToBI a ToBI transcriber for Spanish and Catalan", Language Resources and Evaluation 50 (4), 767-792.

Estebas-Vilaplana, Eva, 2009: "Cuatro niveles de altura tonal en la frontera de frase en español peninsular”, Onomázein 20, 11-32.

Estebas-Vilaplana, Eva, y Pilar Prieto, 2008: “La notación prosódica del español: una revisión del Sp_ToBI", Estudios de Fonética Experimental XVII, 264-283.

FACE, Timothy, y Pilar Prieto, 2007: "Rising accents in Castilian Spanish: a revision of Sp-ToBI" en Gorka EloRdieta y Marina Vigário (eds.): Journal of Portuguese Linguistics (special issue on Prosody of Iberian Languages) 6 (1), 117-146.

Fernandez Planas, Ana María, 2005: "Aspectos generales acerca del proyecto internacional AMPER en España", Estudios de Fonética Experimental XIV, 13-27.

Goebl, Hans, 1981: “Eléments d'analyse dialectométrique (avec application à l'AIS)", Revue de Linguistique Romane 45, 349-420.

Goldman, Jean-Philippe, 2011: "EasyAlign: an automatic phonetic alignment tool under Praat" en Proceedings of InterSpeech, Firenze, Italy.

HART, Johan, René Collier y Antonie COHEN, 1990: A perceptual study of intonation. An experimental-phonetic approach to speech melody, Cambridge University Press.

Hualde, José Ignacio, y Pilar Prieto, 2015: "Intonational variation in Spanis: European and American varieties" en Sonia Frota y Pilar Prieto (eds.): Intonational Variation in Romance, Oxford: Oxford University Press, 350-391.

Martín Butragueño, Pedro, Érica Mendoza y Leonor Orozco (en preparación). Corpus oral del español de México (COEM).

Martínez Celdrann, Eugenio, y Ana María Fernández Planas, 2005: "Estudio metodológico acerca de la obtención del corpus fijo en el proyecto AMPER”, Estudios de Fonética Experimental XIV, 29-66.

Muñoz-BuIles, Diana, y otros, 2017: “El habla ascendente de Chiloé: primera aproximación”, Onomazein 37, 1-15.

Muñoz-BuılLes, Diana (en preparación). Mapa prosódico de Antioquia-Colombia. 
Ortiz, Héctor, Marcela Fuentes y Luisa Astruc, 2010: "Chilean Spanish intonation" en Pilar Prieto y PaoIo Roseano (eds.): Transcription of intonation of the Spanish language, München: Lincom, 255-283.

Otero, Paula López, y otros, 2016: "SEA_AP: a segmentation and labelling tool for prosodic analysis", Dialectologia: Revista Electrónica, 223-244.

Pierrehumbert, Janet, 1980: The Phonology and Phonetics of English Intonation, Cammbridge, Massachusetts: MIT.

Prieto, Pilar, y Paolo Roseano (eds.), 2010: Transcription of Intonation of the Spanish Language, München: Lincom.

Prieto, Pilar, y Paolo Roseano, 2009-2013: Atlas de la entonación del español (ATLES).

Quesada Pacheco, Miguel Ángel, 2014: “División dialectal del español de América según sus hablantes Análisis dialectológico perceptual”, Boletín de Filología 49 (2).

RILlIARD, Albert, s. f.: Interface de la Base de Données AMPER [https://perso.limsi.fr/rilliard/InterfaceAMPER.html].

Román, Domingo, 2013-2016. Mapa prosódico de Chile.

Romano Antonio, Michel Contini y Jean-Pierre Lal, 2012: “L’Atlas Multimédia Prosodique de l'Espace Roman: uno strumento per lo studio della variazione geoprosodica" en Fabio Tosques (ed.): 20 Jahre digitale Sprachgeographie, Berlin: Humboldt-Universität, 27-51.

Wagner, Claudio, 1998: “El Atlas lingüístico y etnográfico de Chile por regiones (ALECH)”, Estudios Filológicos 33, 119-129.

WAGNER, Claudio, 2004: "El atlas lingüístico y etnográfico de Chile. Localidades y cuestionario", Estudios Filológicos 39, 83-120.

Wagner, Claudio, 2005: “Los Estudios Dialectales en la Universidad Austral de Chile”, Documentos Lingüísticos y Literarios 28, 100-103. 